\title{
CARING FOR A PREMATURE CHILD AT HOME: FROM FEAR AND DOUBT TO TRUST
}

\author{
Melva Patricia Ocampo González"1, Edelmira Castillo Espitia ${ }^{2}$
}

\footnotetext{
${ }^{1}$ Master in Child Care Nursing. Professor, Nursing School, Universidad del Valle. Cali, Colombia. E-mail: melvapa67@yahoo. com.mx

${ }^{2}$ Ph.D. in Nursing Philosophy. Retired professor, Nursing School, Universidad del Valle. Cali, Colombia. E-mail: edelcases59@ yahoo.com
}

\begin{abstract}
Being a mother is the result of a process that involves the development of a strong maternal identity, begins during pregnancy, and includes the child's first months of life. This process thrives on the constant mother-child interaction. In order to know the lived experiences of mothers of previously hospitalized premature infants while assuming the child's care at home, a phenomenological study involving ten mothers was conducted. Findings indicate that the separation of the dyad during hospitalization imposes limitations, which prevent women from taking on the new role with confidence and joy. It is important to empower the nursing staff in neonatal units toward implementing strategies for early and continuous mother-child contact that will support women in the process of becoming mothers.
\end{abstract}

DESCRIPTORS: Mother-child relations. Premature. Child care.

\section{CUIDANDO UN HIJO PREMATURO EN CASA: DEL TEMOR Y LA DUDA A LA CONFIANZA}

RESUMEN: Ser madre es el resultado de un proceso que implica desarrollar una fuerte identidad maternal, se inicia en la gestación y abarca incluso los primeros meses de vida del hijo. Este proceso se nutre de la constante interacción madre-hijo. Para conocer las vivencias de las madres de niños prematuros previamente hospitalizados, al asumir el cuidado de ellos en casa, se realizó un estudio fenomenológico con participación de diez madres. Los hallazgos indican que la separación de la diada durante la hospitalización impone limitaciones, que impiden que la mujer asuma con tranquilidad y alegría el nuevo rol. Es importante empoderar al personal de enfermería de las unidades neonatales para implementar estrategias de contacto temprano y continuo madre-hijo, que apoyen a las mujeres en el proceso de convertirse en madres.

DESCRIPTORES: Relaciones madre-hijo. Prematuro. Cuidado del niño.

\section{CUIDANDO UM FILHO PREMATURO EM CASA: DO TEMOR E DA DÚVIDA À CONFIANÇA}

RESUMO: Ser mãe é o resultado de um processo que implica desenvolver uma forte identidade maternal; que se inicia na gestação e envolve, inclusive, os primeiros meses de vida do filho. Este processo se nutre da constante interação mãe-filho. Para conhecer as vivências das mães que tiveram que assumir os cuidados dos bebês prematuros em casa, após a hospitalização, foi realizado um estudo fenomenológico, com a participação de dez mães. Os resultados indicaram que a separação da díade durante a hospitalização impõe limitações que impedem que a mulher assuma com tranquilidade e alegria o novo papel. É importante empoderar o pessoal de enfermagem das unidades neonatais para que implementem estratégias de contato precoce e contínuo mãe-filho, que possam apoiar essas mulheres no processo de converterem-se em mães.

DESCRITORES: Relações mãe-filho. Prematuro. Cuidado da criança. 


\section{INTRODUCTION}

The nursing theorist Ramona Mercer described in details the process undergone by women toward becoming a mother, as well as the variations of such process whenever unfavorable situations resulting from the birth of an ill or premature baby, or a child with congenital malformation are present and demand the infant's hospitalization. ${ }^{1-2}$

According to Mercer, this process may be divided into four phases or stages: the first one is the "preparation and commitment", occurring during the pregnancy, when the woman seeks to adjust her expectations to her new condition. The second phase is the "acknowledgement and physical recovery", immediately following the birth of the child, when the maternal role starts being taken on and learned in the woman's social surroundings. The third stage is the "return to normality", occurring during the first months of life of the baby, when the woman makes all necessary arrangements aimed at adapting her new role to her personal life style. The fourth and last stage is "reaching the maternal identity", when the woman internalizes her experiences and enjoys living her life in a harmonious way and grounded on feelings of competence and trust in her capacity of taking care of the infant. Without the pressures generated by stressors ${ }^{2}$ such process takes place between the baby's fourth and twelfth month of life. However, when a premature child is hospitalized and separated from the mother, situations that directly interfere with the woman's process of becoming a mother emerge. ${ }^{1-2}$ Studies regarding the experiences of mothers who had their newly born babies hospitalized in Neonatal Intensive Care Units (NICUs) allow us to acknowledge the impact produced in their maternal roles, as well as their fears, strengths, expectations and hopes. ${ }^{3-4}$

The hospitalization of an infant in the NICU generally implies the sudden separation of the mother-child dyad and the infant and his/her care become just the healthcare team's responsibility, causing parents, especially the mother, to be considered as visiting relatives who have to comply with timetables and norms of the healthcare institution in order to be able to spend some time with their baby.

There is plenty of evidence that the separation between mother and child during the hospitalization process negatively influences the mother-child interaction, thus generating a delay in the consolidation of the bond between them and the development of the maternal identity. ${ }^{1}$ Therefore, it is very common that when the child's discharge from the hospital is announced, the mothers feel happy but insecure and do not trust their abilities to successfully take care of the infants at home. ${ }^{5-7}$ Also, it has been reported that parents who are allowed to have early and steady contact with and participate in the care process for the premature child in the NICU show confidence and readiness to play their roles of single caregivers at home..$^{6,8-9}$ Hence, healthcare professionals should recognize these facts and offer parents of hospitalized newborn babies the place they deserve to be with their children. ${ }^{10}$

The aim of this study is to describe how mothers who are submitted to stressors, such as the separation from their children and restricted participation in the care for their babies during the hospitalization process at the NICU, experience the care for the infants at home. The study will describe the process experienced by mothers toward building the confidence and the assurance that they will be able to provide their infants the love and necessary care to keep them away from the hospital and growing healthy.

\section{METHODOLOGY}

The study methodological design was the Interpretive Phenomenology based on Martin Heidegger's philosophy. ${ }^{11}$ As a research method, the aim of Interpretative Phenomenology is to "comprehend daily abilities, practices and experiences, as well as articulate the similarities and differences existing in the meanings of human beings' experiences". ${ }^{12: 32}$ For Heidegger, the world is not unique or universal; it is otherwise distinct for each human being as a result of his/her culture and historical time, as well as the family he/ she was born in. Hence, the way of "being" in the world is guided by the meaning assigned by each person to things and situations. ${ }^{12}$ Heidegger affirms that each person builds the meanings of his/ her experiences based on his/her own culture and supported by every form of expression available, thus giving significance to each lived experience according to his/her feelings and thoughts and within his/her social context. Phenomenological studies enable us to address the essence of human phenomena, allowing us to acknowledge, understand and describe them the way they appear to the experiencing person's consciousness. ${ }^{12}$

Ten mothers aged 18 through 37, participated in the study. Such number of participants allowed for the saturation of the data, that is, the information offered by the participants reached the limit of evidences, issues or nuances regarding 
the researched phenomenon.

Inclusion criteria were: to be over 18 years old and mother of a premature newborn child hospitalized in an NICU at least for two weeks, who did not demand special care after being discharged from the NICU; the mother should be the infant's caregiver. Before starting the data collection process, compliance of the inclusion criteria was checked and the potential participants were contacted so that they could receive explanation about the research, be invited to participate in the study and signed the informed consent. Each participant was handed a copy of the informed consent.

The next step was the definition of the first meeting with each participant, when the questionnaire containing the socio demographic information was filled out and the first in-depth interview were carried out. Qualitative information was collected by means of two in-depth interviews with each participant that lasted between 45 and 90 minutes. The interviews were recorded by a digital recorder and then textually transcribed. In order to protect the identity of participants, codes were employed instead of names. Each interview was done according to a thematic guideline. However, during the interviews, mothers were allowed to speak freely and spontaneously. The researcher followed the participant's descriptions until the largest amount of details and broadest and enough narratives on each aspect mentioned by the mother. The purpose of such exhaustive approach was to describe how mothers dealt with the experience of being responsible for taking care of premature children at home, following the babies' hospitalization process at the NICU, and which their practices and feelings about it had been.

The analysis of the information was carried out in two moments: 1) during the data collection process, after the literal transcription of each interview was checked out, the text was analyzed so that the understanding of the lived experiences of each participant could be initiated and eventual unclear aspects could be clarified, deepened or confirmed in the second interview; and 2) at the end of the data collection process, when a further analysis an interpretation of the transcription of interviews was carried out. For that purpose, the transcriptions of interviews were fully read several times, so that the experiences of each participant could be comprehended and their stories more accurately told. Subsequently, similarities, differences and patterns were identified in the stories of the participating mothers, allowing for the dis- covery and description of their lived experiences about caring for their children at home.

In order to be methodologically rigorous, the researchers took into account internal validity criteria, such as the full compliance with the description fidelity of the participants' lived experiences. For this reason, all interviews were recorded and transcribed, and the participants approved the final interpretation of their lived experiences produced by the researchers. ${ }^{13}$ The auditing criteria, which is enabled by the possibility of accessing the written and voiced records when the data analysis is requested, also the collection, analysis of the data, and the results writing process have been followed very closely by a researcher with over ten years of experience with phenomenological studies. Finally, as for the transferability criteria or external validity, other mothers who had experienced this phenomenon validated the findings produced by the study.

The study was approved by the Institutional Committee of Human Ethics Review of the Health Science Division of the Valle University, Cali, Colombia, under protocol number 121-09.

\section{RESULTS}

Characterization of participants: as for the educational level, one mother was illiterate, six had not completed high school, two had technical degrees and one was a healthcare professional. Four out of the ten women had a common law marriage, one was separated, two were single, two were married, and one was a widow. For six women, it was their first pregnancy, for three of them it was their second pregnancy, and one of them had been pregnant for three times. Two women had already experienced the situation of having a premature child. Six children were born by C-sections. The gestational age of the children varied from 28 and 34 weeks, calculated by the Ballard assessment carried out in the first 48 hours of life of the baby at the NICU. Weight at birth ranged from 670 to 1,495 grams. The hospitalization of the infants, in average, reached 34.2 days, with the longest time being 75 days and the shortest 16 days. The children were hospitalized at a level-III NICU, which allowed for parents to see the children for 30 minutes every day.

A description about how the mothers lived the process of taking care of their children at home is presented as it follows. During this time, they started having feelings of insecurity and fear. Then, several weeks later, they were able to become capable and confident mothers that could 
care for their infants.

The first night at home the mothers were caring their child after discharge from the NICU, was a long one, full of anguish and uncertainties. The mothers described it as the worst night ever in their lives; however, they successfully overcame it with dedication and commitment. The next morning, they got ready to go back to the hospital for the visit to the "High-risk follow-up program", aimed at carrying out the first health control of their children. They were exhausted, had many questions and doubts, and feared that their child had lost weight or would have any complication that could force to leave him/her in the hospital. However, they went back home relieved by the positive reinforcement of the healthcare professionals and having answers to the doubts they had the night before.

On the initial days, the infant still looked tiny, thin, with visible veins all around the body, very "soft" and fragile, according to the mothers' perception. They recognized their clumsiness to change the baby's position, hold him/her to get free of gases even to dress him/her up. Mothers were scared at the possibility of hurting the baby, and felt useless even to carry him/her, move it from one position to another, roll it over on the bed, or accommodate it on their arms; but, they were aware that they should do all this with their babies. Mothers also experienced joy and calmness for not having to be kept all day at the hospital and wait to see their child for such a short period of time, or thinking about potential procedures that could end up abbreviating or cancelling their visit to the baby, or even the possibility of getting back home without the child. Now, they were able to sit down and watch sleep, sing a lullaby or sleep with them in the moment and the time they wanted.

In their daily experience, mothers had many fears. In the beginning, they feared that any involuntary injury could be done to the baby due to their clumsiness. For instance, they feared that the baby would get a fracture since his/her fragileness includes his/her bones, lungs and the head which they felt so soft. Such fear started being minimized as they felt more secure while touching and moving the baby and the baby started gaining weight and muscle tone. Nevertheless, some fears took a long time to go away, such as the fear of the possibility that the child having apnea due to a wrong positioning, and above all the fear of having to take the child back to the hospital. Such fear was constantly present in all mothers and lasted for months in a few of them. The fear was not solely that of being separated from the child, but the risk of the infant dyeing due to any wrongdoing on their part or something they should have done and did not do.

\section{[...] I fear not only the possibility of being without} the baby, I fear that the baby-girl is not okey, you know. I'm afraid I can do something wrong, like not giving her food as she should receive, if she is cold, because I went out with her, then I thought she could get sick... I was afraid I was failing her, something that could harm her. I was afraid she could not be well, be ill [...] (e3a).

Mothers very quickly realized that they were the only ones responsible for taking care of their child. At their places, they all listened to expressions such as: she is the one who knows it, she was the one they taught how to deal with it. The child's father, aunts, uncles and grandparents were afraid of touching and holding the baby; yet, they were always ready to collaborate with the preparation of the bottle, to organize the carrycot or the cradle, to wash clothes or help with the home chores, so that the mother was able to focus on caring for the infant.

[...] they do not dress him, do not bathe him, they do nothing. The baby may be full of poop... [be with] the same dirty clothes of the past day. Mónica, Mónica, Mónica, change the baby's clothes, change his diapers, take his rompers out, wipe his nose...it's all on me. They are afraid of touching his head, raise him up in order to put the cap on. I am stressed at touching the baby's head myself, but I'm already used to hold him. The same goes for when he is coughing, or drowning... It's all on me [...] (e2a).

None of the mothers referred to their responsibility of taking care of the baby in a negative way. But, all of them pointed out their intense physical exhaustion and the high level of stress and preoccupation regarding the wellbeing of the child, although none of them perceived their activities as a burden, an obligation or a punishment.

[...] when I lay down, I close one eye and keep the other one wide open. The whole body, the eyes, the ears are all there, stuck with the baby. If I hear that he turns, I wake up in order to see what is going on. The carrycot is quite close to my bed, practically on it, I'm wired to him [...] (e1b).

For these women, feeding their child was the most demanding practice in the first days. The vast majority of the children took one hour or more to sufficiently drink the bottle's milk, and the gas expelling process was also complicated. Nonetheless, the mothers were quite patient and understood that they should keep their babies awake before feeding them, and then started improving both techniques: the feeding and the gas expelling processes: 
[...] I did not sleep the whole night, especially because she received milk in the bottle every two hours, you know. So, I woke up with all the patience in the world and as they feed so slowly I had to spare one and a half hour to give her the milk and expel gases. Then I would go back to bed and she kept moving, and I kept looking at her. And then it started all over again [...] (e4b).

Initially the mothers did not understand the child's behavior, and as such what they had been taught at the hospital did not make any sense. But, as time passed by, they gradually started to understand the behavior of the infants and then were able to know if they had had enough food, if they wanted more milk, whether or not the babies were lazy to feed but were feeling well, or if they should poo prior to get fed. The mothers understood that the key secret to know what they should do was to pay constant attention to their child, and then check out which recommendation provided by the hospital would best fit the infant's behavior characteristics.

[...] as time passes by, we start learning the child's language, even though they do not speak, they send messages all the time. At least, we begin to understand that he wants more food, the amount he needs, you know. We start learning, but you have to be there, at the night shift, even being awaken all night long, in order to learn. So, even though they do not speak yet, they convey information [...] they really can't talk [...] but if they do not receive enough food they make us crazy, when they are hungry, or when we don't give them enough milk. But, this only happens when we are right there, paying attention to them, we have to be around all the time before we can really understand their messages [...] (e3b).

Only three mothers were breastfeeding their child at the time they got out of the NICU. They noticed that even though the infant was able to grab the nipple, he rapidly let it go and started crying; in spite of insisting, the mothers were unsuccessful either to calm him down or breastfeed him. So, they offered the bottle to the baby and he would sustainably suckswallow the milk, and then fell asleep. Even so, the mothers kept attempting to breastfeed the baby for a couple of days, until their milk was gone.

The feeding issue was quite critical to assess the mother's care for the child, as he depended on it to gain weight and such parameter was used in the hospital to decide whether or not the infant could go home with his mother. The mothers were very aware that if the child did not gain weight they would risk his health and consequently he would be kept in the hospital, and they would suffer again with the separation. The mothers had this concept very clearly stated, and as such they did not spare any effort to- ward feeding the child over day and night with the sufficient amount of milk and without vomiting it.

Another relevant aspect of the child's care at home was to keep the baby warm. The mothers were repeatedly instructed at the hospital that premature children are not capable of keep their bodies warm on their own, and that parents should do their best in order to keep the babies warm, thus preventing alterations of breathing patterns and loss of weight. In order to avoid such losses of body temperature, the mothers knew that they should not bathe the infants until they were 40 weeks old, that is, until the real birth time was fulfilled. During this time, mothers were instructed to only clean them with humid cloth. The cleaning and dressing processes of an infant should be made inside closed doors; the clothes should be warmed before being put on the child, and the clothes should be made of thermal materials. The baby should wear two shirts, two jackets, two pants and in some occasions, two caps. Finally, the baby should use thermal blankets.

[...] well, if the baby girl is cold, she'll spend more energy and will lose weight, but what is the idea? The idea is that she gains weight so she is not kept in the hospital [...]. Then, I simply stopped, and listed everything we needed. The idea was to dress her with warm clothes so that she did not get cold. If dad was around, I checked out what he was doing. If he was watching TV, well, I placed the clothes here [on his chest] until they were warm enough to dress the baby. And it should be done very fast, so that she did not lose any heat. Then, she was cleaned with two moisturized towels, one for her face and the other for her body, and there you go (e5b).

For the mothers, dressing the child became easier and easier. Some of them learned to put on one garment first, and then the second one; others rolled the child over while dressing him up. On the first days, it took them a long time to do it. As time passed by, however, when they started realizing that their movements would not hurt the babies, they started doing it faster and faster.

There's more. I clearly remember one night, when it was very cold. Then, what we did was to place a lamp at the baby's carrycot, so that it could provide him with more heat. It was very cold indeed. So, the father said, well, it's like warming up a little chick, and that was it (e1a).

During hospitalization and when the mothers attended the "High-risk follow-up program" at the healthcare institution, they were informed that when the children reached the $40^{\text {th }}$ week, it would be like a second birth, and from that day on their care process would undergo some changes. 
The infant would have grown and, as a result, to hold, carry and change his clothes would be quite a simpler task. Some activities would be carried out in longer time intervals and other activities would begin. As such, from the day the child reached the $40^{\text {th }}$ week, mothers would feed him/her at every three hours; therefore the two-hour interval mothers were used to underwent quite a relevant change. Additionally, at this time, the baby could suck much better and could drink the indicated amount of milk in quite a quicker way. The number of people that could now interact with the infant also increased. And now the baby could already be bathed in the tub and be dressed up more conveniently, not needing anymore the double clothing that made him look like a bundle of fabrics. Finally, the baby could wear the clothes given by family members and friends. On the other hand, the child also started having short alert periods, in which the mother could play or talk to him. After 40 weeks, both the mother and the baby have longer night periods of rest, and even though the mothers were still fearful for the risk of the baby having bronco aspiration and thus kept vigilant, they understood that reaching 40 gestational weeks allowed them to take care of their child as a normal baby.

From the day the baby reached the 40th week on, the day she should have been born, we started expanding the feeding time to three hours and we started organizing the night shift in a better way. For instance, to bathe her before her sleep time, so she could sleep better. Before that, we were very much afraid, she was very vulnerable to everything $[. .$.$] and then we didn't do it [...]. That was$ a starting point and we then began to be less worried about her, or not overprotective of her anymore (e6b).

Although their child was so young, the mothers started exploring several different ways of showing them their love, such as playing with little bells and teddy bears, making up songs, reading stories, and even praying for a superior being in gratitude for the overcome tests and always asking for help and divine protection for their baby.

Slowly, but steadily, the mothers started understanding that the answers to their doubts were located in their capacity of comprehending the child's language, and that it was important to observe him in a permanent, detailed way, so that his needs could be met.

[...] when she cried very much, there were plenty of possibilities. Because you don't know when they are crying as a result of pain, or hunger, because both are quite distinct. They are distinct because when they are crying as a result of pain, it goes like an acute "yeoww- $w w w "$. When they are hungry, we offer the bottle. But sometimes she cries and someone gives her the bottle and she refuses it, she doesn't want it. Then, we know that she is suffering from pain. Once she had a constipation... and I knew when she was crying because of that $[. .].(\mathrm{e} 5 \mathrm{~b})$.

The positive feedback provided by the professionals at the hospital's follow-up program was very meaningful for the mothers to feel safe and confident in taking care of their child. Whenever they were congratulated for their successes with the infant, they felt assured, happy, and their trust in their capacities increased. It was like being rewarded by all efforts and sacrifices, and they were very proud of the care they were providing to their baby. Spouses, family members, friends and other women participating in the follow-up program, in addition to neighbors, uttered encouraging comments on the child, which motivated mothers significantly.

[...] when I am told that the baby girl looks beautiful, I say that it was worth it, that is, it was worth to be awake every night, have many sleepless nights, a real battle, because it is a battle, and not only that, it was up to me to bring her here [the hospital] two times a week to be weighed, two times a week. For me, it was very stimulating when I came here and I was always congratulated, they always congratulated me. Another mother also brought her baby girl and they always nagged at her. Not me. So, it was worth it, you know. The other mother was scolded, see how weak your baby is, and so on. And this mother talked to me, and said that she would not offer her breast to the baby anymore, because she vomited, and vomited, and vomited, and vomited [...] (e9a).

Another source of self-assurance and trust for the mothers arose from the child's progresses. The baby's weight gain and his increased size pointed out to their successes. Besides, as weeks went by, the child changed and started displaying enhanced behaviors, such as to gaze at the mother's face, to recognize her voice, and to calm down at hearing her. Subsequently, smiles, giggles, and the turnings on the bed started to happen, that is, all the social and motor achievements for the child's corrected age, which were experienced by the mothers as the happiest moments they had since the birth of the child. And they were joyful for being able to be there and see that all.

It took mothers an average of seven weeks to feel confident and capable of taking care of the child at home. The period was a little shorter for women who already had other babies and for one healthcare professional, and a little bit longer for one of the adolescent mothers. The progress toward becoming mothers implied several changes 
in the woman's life style, including reassessing their motivations, needs and expectations. The child had become the center of their lives.

[...] I mean, well, I'd like to go out today, but as I have a baby I cannot do that anymore. Hmm, in the past I would do anything to buy an item I craved for at the store, now it's all the way around, I can't go downtown anymore because I have to take something back home for my daughter. So, I say, well, I want this for my baby [...] (e7b).

Having control of the baby's care, in others words, to decide, to act calmly, to be confident and feel secure was a consequence of the articulation of several different elements, namely, getting to know their child as a result of a repeated, attentive observation of his behavior hour after hour; patience and perseverance of the mothers while carrying out the daily care activities; the support offered by the healthcare professionals at the high-risk follow-up program; the interaction with other mothers of premature children; and the encouraging words provided by the spouse, family members and friends.

\section{DISCUSSION}

The findings of this research describe the way the separation of the mother-child dyad in the neonatal phase restricts the advancement of the process of becoming a mother. The lack of interaction between mother and child reduces the opportunities of getting to know the baby and caring for him/her, making it difficult for the woman to adjust to her new role of being a mother. Women separated from their hospitalized infants describe their doubts, insecurity and fear while they begin to be responsible for the care of their children at home, since they lack opportunities to develop the security and joy that women are expected to display whenever they are able to adequately experience the process of internalizing the maternal role. In average, the mothers participating in the study needed seven weeks to start feeling comfortable and secure to take care of their infants at home, after the return of their children from the neonatal unit. Such findings are similar to those described by other researchers, who report the difficulties mothers undergo to establish a bond with their children when they do not have a close contact with them right after their birth, ${ }^{1,4,7}$, the feeling of impotence toward caring for the child at home after the infant is discharged from the hospital, ${ }^{5-6,8,10}$ the doubts and uncertainties as to how to perform some care activities and how to modify them as the baby grows and changes, as well as the feeling of not being a real mother but a fearful person that is incapable of taking care of her child without the support of healthcare professionals. ${ }^{4-6,14-16}$

Throughout the pre and postnatal period, the professional nurse is recognized as the one being in more contact with the woman. For this reason, nursing should lead the actions aimed at supporting the women going thru the second and third phases of the process of becoming a mother. For instance, allowing the woman to stay longer with the child at the NICU, so that she is able to be constantly in contact with the baby and provide him with direct care and the nurses could give her positive feedback. ${ }^{1-2}$ Caring for a child hospitalized in a NICU implies to affect positively the health of two human beings: the mother and the infant. ${ }^{1-2}$ Strategies should be developed toward supporting the woman's progress in the process of becoming a mother, despite the baby's prematurity and the hospitalization itself. The separation of the motherchild dyad should not be a norm at the NICU. On the contrary, all efforts should be made toward promoting a permanent contact between mother and child, thus providing the mother with the opportunity of caring for her baby..$^{1-2,16-17}$

Nurses should know and based their practice in adequate theories that provide them with a solid knowledge foundation toward helping women to succeed in their identity building process as mothers, in spite of the difficulties that may surround the birth and the hospitalization of their premature baby. There are several strategies that may be employed to yield an early and continuous contact between mother and child. One of them is the skin-to-skin contact, or the so-called kangaroo care. Researchers affirm that it is ideal for the strengthening of ties between the mother and the baby, as well as for the participation and empowerment of parents to care for their child, thus contributing to the healing and development process of both. ${ }^{17-20}$

The nurses at the NICU can employ the kangaroo care as a strategy to facilitate the women's path during the acknowledgement and physical recovery phase of the becoming a mother process, to provide an harmonious environment that would help women to go into the returning to normality phase, that is, when women accommodate the mothering role into their personal life style.

\section{CONCLUSIONS}

The findings of this study indicate how the separation of a mother from her premature child 
hospitalized in the NICU is perceived by her as an obstacle in the process of becoming a mother. Nonetheless, getting to know the child by means of a repeated and detailed observation of his/her behavior, the patience and perseverance of the mothers throughout the daily care processes, the support given by both the professionals at the baby's follow-up program and other mothers of premature children, spouse, family members and friends, as well as the opportunity of observing the development and growth of the child, all grant the mother the possibility of becoming a competent, confident and secure mother for herself and everyone around her.

Even though the results of this study cannot be generalized, it is reasonable to take into account that they are replicated in many other NICUs with similar contexts to the NICU where this research took place, as all the vast majority of NICUs in Colombia and other Latin American nations. However, other studies should be carried out, aiming at investigating what mothers and fathers of premature children hospitalized in NICUs experience in contexts where it is allowed permanent contact and participation of both parents in the care for the child allows vis-à-vis contexts where the above mentioned contact is rarely practiced.

\section{REFERENCES}

1. Miles MS, Holditch-Davis D, Burchinal MR, Brunssen $S$. Maternal role attainment withmedically fragile infants. Res Nurs Health. 2011 Feb; 34(1):20-34.

2. Meighan M, Mercer R. Maternal role attainmentbecoming a mother. In: Alligood MR, Tomey AM. Nursing theorists and their work. Maryland Heights, MO: Mosby Elsevier; 2010. p. 581-97.

3. Ocampo MP. El hijo ajeno: vivencia de madres de niños prematuros hospitalizados. Aquichán. 2013 Abr; 13(1):69-80.

4. Gallegos J, Reyes J, Silvan CG. La unidad neonatal y la participación de los padres en el cuidado del prematuro. Perinatol Reprod Hum. 2010; 24(2):98-108.

5. Sáenz P, Cerdá M, Díaz JL, Yi P, Gorba M, Boronat $\mathrm{N}$, et al. Psychological stress of parents of preterm infants enrolled in an early discharge program from the neonatal intensive care unit: a prospective randomized trial. Arch Dis Child Fetal Neonatal Ed 2009 Mar; 94(2):98-104.

6. Sneath N. Discharge teaching in the NICU: are parents prepared? An integrative review of parents' per- ceptions. Neonatal Netw. 2009 Jul-Aug; 28(4):237-46.

7. Wakely LT, Rae K, Cooper R. Stoic survival: the journey of parenting a premature infant in the bush. Rural Remote Health. 2010 Jul-Sep; 10(3):1475.

8. Sassá AH, Marcon SS. Evaluation of families of infants with very low birth weight in home care. Texto Contexto Enferm. [online]. 2013 Jun [cited 2014 Jun 20]; 22(2):442-51. Available from: http:/ / www. scielo.br/scielo.php?script=sci_arttext\&pid=S010407072013000200021\&lng=en

9. Bystrova K, Ivanova V, Edhborg M, Matthiesen AS, Ransjo-Arvidson AB, Mukhamedrakhimov R, et al. Early contact versus separation: effects on mother-infant interaction one year later. Birth. 2009; 36: 97-109.

10. Raines DA. Preparing for NICU discharge: mothersconcerns. Neonatal Netw. Springer Publishing Company. 2013 Nov-Dec; 32(6): 399-403.

11. Heidegger M. Ser y tiempo. México (MX): Fondo de Cultura Económica; 2005.

12. Castillo E. La fenomenología interpretativa como alternativa apropiada para estudiar los fenómenos humanos. Invest Educ Enferm. 2000 Mar; 18(1):27-35.

13. Guba EG, Lincoln YS. Naturalistic inquiry. Newbury Park (CA): Sage; 1985.

14. López G, Anderson K, Feutchinger J. Transition of premature infants from hospital to home life. Neonatal Network. 2012 Jul-Aug; 31(4):207-14.

15. Levick J, Quinn M, Vennema C. NICU parent to parent partnerships: a comprehensive approach. Neonatal Network. 2014 Mar-Apr; 33(2):63-73.

16. Discenza D. Taking care of the NICU mom. Neonatal Network. 2009 Sep-Oct; 28(5):351-2.

17. Nyqvist K, Anderson G, Bergman N, Cattaneo A, Charpak N, Davanzo R, et al. Towards universal Kangaroo Mother Care: recommendations and report from the First European Conference and Seventh International Workshop on Kangaroo Mother Care. Acta Paediatrica. 2010; 99:820-6.

18. Discenza D. Kagaroo care: worth the time and effort. Neonatal Network. 2012 May-June; 31 (3):189-90.

19. Conde-Agudelo A, Díaz-Rossello JL. Kangaroo mother care to reduce morbidity and mortality in low birthweight infants. Cochrane Database of Systematic Reviews [on line] 2014 [acceso 2014 May 10]; 4(CD002771). Available from: DOI 10.1002/14651858.CD002771.pub3

20. Arivabene JC, Rubio Tyrrell MA. Método madre canguro: vivencias maternas y contribuciones para la enfermería. Rev Latino-Am Enfermagem [online]. 2010 [acceso 2014 May 10]; 18(2): Available from: http:/ / www.scielo.br/pdf/rlae/v18n2/es_18.pdf 